\title{
CARACTERÍSTICAS MORFOGÊNICAS E ESTRUTURAIS DO SORGO FORRAGEIRO SUBMETIDO A LOTAÇÃO CONTÍNUA COM NOVILHOS DE CORTE SUPLEMENTADOS
}

\section{MORPHOGENIC AND STRUCTURAL CHARACTERISTICS OF SORGHUM FORAGE SUBMITTED TO THE CONTINUOUS LOTATION WITH SUPPLEMENTED BEEF STEERS}

\author{
Ana Paula Machado Martini ${ }^{1^{*}}$ ORCID - http://orcid.org/0000-0002-1963-9424 \\ Ivan Luiz Brondani² ORCID - http://orcid.org/0000-0002-6526-3042 \\ Viviane Santos da Silva² ORCID - http://orcid.org/0000-0002-5401-952X \\ Dari Celestino Alves Filho² ORCID - http://orcid.org/0000-0003-2559-7504 \\ Patrícia Machado Martini² ORCID - http://orcid.org/0000-0002-0648-4064 \\ Flânia Mônego Argenta ${ }^{3}$ ORCID - http://orcid.org/0000-0002-0150-6607
}

\author{
${ }^{1}$ Universidade Tecnológica Federal do Paraná, Dois Vizinhos, PR, Brasil. \\ ${ }^{2}$ Universidade Federal de Santa Maria, Santa Maria, RS, Brasil. \\ ${ }^{3}$ Instituto Federal de Educação, Ciência e Tecnologia do Rio Grande do Sul, Vacaria, RS, Brasil. \\ *Autora para correspondência - anapaulamartini@zootecnista.com.br
}

\section{Resumo}

A morfogênese é uma valiosa ferramenta para a compreensão da dinâmica do pasto, porém os estudos morfogênicos referentes à cultura do sorgo ainda são escassos. O objetivo do presente estudo foi avaliar os efeitos de diferentes níveis de suplementação sobre as características morfogênicas do sorgo forrageiro. O experimento foi conduzido na Universidade Federal de Santa Maria entre janeiro e abril de 2013. O delineamento experimental foi inteiramente casualizado, com medidas repetidas no tempo, com três tratamentos e duas repetições. Os tratamentos consistiram em S 0,8= pastagem de sorgo $+0,8$ \% PV de suplementação, S 1,0 = pastagem de sorgo $+1,0$ \% PV de suplementação e S 1,2 $=$ pastagem de sorgo $+1,2$ \% PV de suplementação. Ao aumentar o nível de suplementação ofertado, observou-se menor valor para Folhas Vivas $(2,77,3,34$ e 3,55) e Taxa de Elongação Foliar $(0,06,0,09$ e 0,08$)$. Não foram influenciadas $(\mathrm{P}<0,05)$ pelos diferentes níveis de suplementação as variáveis Taxa de Aparecimento Foliar (0,0041, 0,0043 e 0,039), Taxa de Senescência Foliar (0,05, 0,06 e 0,11), Filocrono (283,96, 265,21 e 278,62), Duração de Vida da Folha (1081,1, 986,25 e 788,79) e Duração de Elongação Foliar (350,58, 312,83 e 326,36).

Palavras-chave: Filocrono. Pastagem de clima tropical. Níveis de suplemento. Dossel. Taxa de alongamento foliar.

\begin{abstract}
Morphogenesis is a valuable tool for the dynamics understanding of the pasture, however the morphogenetic studies related to sorghum culture are still scarce as well. The objective of the present study was to evaluate the effects of the different levels of supplementation on the morphogenetic characteristics of sorghum forage. The experiment was performed of UFSM from January to April 2013. The completely randomized experimental design was used, with measures repeated in time, with three treatments and two repetitions. The treatments consisted in S $0.8=$ sorghum pasture + $0.8 \% \mathrm{LW}$ of supplementation, S $1.0=$ sorghum pasture $+1.0 \% \mathrm{LW}$ of supplementation and S $1.2=$ sorghum pasture $+1.2 \% \mathrm{LW}$ of supplementation. By increasing the supplementation level offered it
\end{abstract}


was observed a lower value for the Number of Live Leafs (2.77, 3.34 and 3.55) and Leaf Elongation Rate $(0.06,0.09$ and 0.08$)$ characteristics. The variables Leaf Appearance Rate $(0.0041,0.0043$ and 0.039), Leaf Senescence Rate (0.05, 0.06 and 0.11) and Phyllochron (283.96, 265.21 and 278.62) were not influenced $(\mathrm{P}>0.05)$ by the different supplementation levels. There was a difference $(\mathrm{P}<0.05)$ among the evaluation periods for Leaf Life Span (1081.1, 986.25 and 788.79) and Leaf Elongation Length $(350.58,312.83$ and 326.36).

Keywords: Phyllochron. Tropical pastures. Supplement levels. Canopy. Leaf elongation rate.

Recebido em: 31 de janeiro de 2017.

Aceito em: 10 de junho de 2019.

\section{Introdução}

A Bovinocultura de Corte no estado do Rio Grande do Sul tem como principal base alimentar as pastagens nativas constituintes do bioma pampa, que apresentam grande diversidade florística e bons índices produtivos durante as estações quentes ${ }^{(1)}$. Entretanto, essa base forrageira pode apresentar deficiências produtivas e/ou nutricionais que podem ser limitantes para o desempenho dos animais, por exemplo, retardando a idade de abate.

O uso de pastagens cultivadas de estação quente, como o sorgo forrageiro (Sorghum bicolor L. Moench), pode auxiliar a produção pecuária de bovinos de corte e maximizar a produtividade dos sistemas de produção, especialmente por se tratar de uma espécie do tipo C4, com altas taxas fotossintéticas. A cultura se adapta a uma variedade de ambientes produzindo razoavelmente bem sob condições desfavoráveis, apresentando níveis de PB entre $8 \%$ e $15 \%{ }^{(2)}$ e NDT entre $60 \%$ e $70 \%{ }^{(3)}$. Dessa forma, o sorgo pode apresentar um amplo espectro na qualidade forrageira, sendo uma fonte alimentar de qualidade para bovinos de corte ${ }^{(2)}$.

A produtividade de uma gramínea decorre da contínua emissão de folhas e perfilhos, processo importante após o corte ou pastejo para restaurar a área foliar da planta ${ }^{(4)}$. Assim, o entendimento dessas características permite ao técnico uma visualização da curva de produção, acúmulo de forragem e uma estimativa da qualidade do pasto.

A caracterização das espécies forrageiras através das avaliações morfogênicas são importantes auxiliares para elaboração de estratégias e tomada de decisões para melhor explorar o seu potencial produtivo. Principalmente quando realizadas em ensaios de suplementação animal, buscando assim fornecer subsídios para o entendimento da relação entre o manejo adotado e as respostas produtivas da planta e dos animais ${ }^{(5)}$. Isso porque a suplementação alimentar dos animais afeta o consumo do pasto, podendo influenciar suas características produtivas e estruturais ${ }^{(6)}$. Outro fator que evidencia a importância dessas avaliações é quando são realizadas em espécies pouco estudadas, como é o caso do sorgo forrageiro ${ }^{(7)}$.

Diante das evidências apresentadas, o presente estudo se propôs avaliar as características morfogênicas e estruturais da pastagem do sorgo forrageiro e os efeitos de diferentes níveis de suplementação, utilizando novilhos de corte sob lotação contínua. 


\section{Material e métodos}

O experimento foi conduzido durante o período de 27 de janeiro de 2013 a 28 de abril de 2013, no Laboratório de Bovinocultura de Corte (LBC) pertencente ao Departamento de Zootecnia da Universidade Federal de Santa Maria (USFM), localizada na região fisiográfica denominada Depressão Central, no estado do Rio Grande do Sul, com altitude de 95 m, latitude $29^{\circ} 43^{\prime}$ Sul e longitude $53^{\circ}$ 42' Oeste.

O solo da área experimental é classificado como Argissolo Vermelho Distrófico Arênico ${ }^{(8)}$. O clima da região é Cfa (subtropical úmido), conforme classificação de Köppen ${ }^{(9)}$. Os dados climatológicos foram obtidos junto à Estação Meteorológica da Universidade Federal de Santa Maria e o Instituto Nacional de Meteorologia (INMET).

A implantação da pastagem de sorgo forrageiro (Sorghum bicolor L. Moench) cv. AS4560 foi realizada em 10 de dezembro de 2012 na forma de plantio direto, com espaçamento entre linhas de $47 \mathrm{~cm}$ e densidade de $16 \mathrm{~kg} / \mathrm{ha}$ de semente.

O manejo de adubação foi realizado para correção dos nutrientes do solo, com base na análise química realizada em novembro de 2012, que apresentou os seguintes valores: $\mathrm{pH}$ em $\mathrm{H}_{2} \mathrm{O}=4,66 ; \mathrm{P}=9,86$ (Mehlich-1); $\mathrm{K}=81,3 \mathrm{mg} / \mathrm{dm}^{3} ; \mathrm{Ca}^{2}=6,16 ; \mathrm{Al}_{3}^{+}=1,8 \mathrm{cmol} / \mathrm{dm}^{3}(\mathrm{KCl} 1 \mathrm{~mol} / \mathrm{L})$. Na implantação foram utilizados $150 \mathrm{~kg} / \mathrm{ha}$ de N-P-K fórmula 5-20-20. A adubação de cobertura de $150 \mathrm{~kg} / \mathrm{ha}$ de ureia, realizada em três aplicações, em 06 de março 2013, 22 de março de 2013 e 07 de abril de 2013 e uma de $30 \mathrm{~kg} /$ ha de fertilizante N-P-K fórmula 5-20-20, em 22 de março de 2013.

Foram avaliados seis piquetes nos quais permaneceram dois novilhos testers (acrescido de reguladores quando necessário), pertencentes a cruza Charolês x Nelore, com idade e peso médio inicial de 16 meses e $352,19 \mathrm{~kg}$ respectivamente, tomados ao acaso do rebanho experimental do Laboratório de Bovinocultura de Corte. Ao término do experimento os animais foram para abate, com peso médio de $404,65 \mathrm{~kg}$.

Os tratamentos consistiram em S 0,8 = pastagem de sorgo + 0,8 \% Peso Vivo de suplementação; $\mathrm{S} 1,0=$ pastagem de sorgo $+1,0 \%$ Peso Vivo de suplementação e S 1,2 = pastagem de sorgo + 1,2 \% Peso Vivo de suplementação, constituída de $82 \%$ de grão de aveia branca, 15 \% grão de milho moído e $8 \%$ de calcário calcítico, apresentando a seguinte composição química: 115,49 (g/kg de MS) de PB, 112,10 (g/kg de MS) FDNcp, 503,03 (g/kg de MS) de NDT e 32,40 Mcal de ED.

O método de pastejo foi o contínuo, com lotação variável, seguindo a técnica "put and take"(10). As massas de forragem foram mantidas constantes ao longo do experimento com valor médio de $548 \mathrm{~kg}$ de MS/ha, enquanto a carga animal média foi de $866,9 \mathrm{~kg} / \mathrm{ha}$ de peso vivo.

Os piquetes foram sorteados aleatoriamente, dois de cada tratamento, sendo demarcados 50 perfilhos com fios coloridos em cada um deles ${ }^{(11)}$. Os perfilhos foram distribuídos aleatoriamente em três transectas (linhas) por piquete, totalizando 100 perfilhos por tratamento. A primeira folha de cada perfilho foi marcada com corretor ortográfico à base de água, como referência sobre a ordem de distribuição das folhas no dossel do perfilho.

A primeira avaliação foi realizada quando os animais entraram na pastagem. Com auxílio de uma régua graduada em $\mathrm{cm}$ e a cada sete dias, foram realizadas as medições de comprimento de folha madura, medida a partir da lígula até o ápice da folha; no caso de folhas em expansão, o mesmo procedimento foi adotado, porém considerando a lígula da última folha expandida como referencial 
de mensuração. Para folhas em senescência, o comprimento correspondeu à distância entre o ponto onde o processo de senescência avançou até a lígula da folha (medição da porção verde da lâmina foliar). As folhas foram classificadas como: adulta (presença de lígula), jovem (ausência de lígula) ou morta (mais de 50\% de senescência), para essa determinação tanto folhas intactas quanto as pastejadas foram consideradas.

A Altura do dossel (ALDOS) foi medida a partir do nível do solo até o dobramento médio das folhas superiores; Comprimento do pseudocolmo (CPC) foi determinado pela distância da superfície do solo até a lígula da folha mais jovem completamente expandida, incluindo o colmo mais o pseudocolmo. O comprimento final da lâmina foliar (CFL) foi determinado pelo comprimento médio de todas as folhas vivas, calculada pela diferença entre a altura média do pasto (dossel) e a altura do pseudocolmo.

A partir das medidas realizadas a campo foi possível determinar as seguintes variáveis: Número de folhas vivas (NFV) - soma de folhas adultas e jovens; A Taxa de aparecimento foliar (TApF) - razão do número de folhas surgidas no período pelo número de dias do período; filocrono - razão entre 1 e a taxa de aparecimento foliar

A Duração de vida das folhas (DVF) - produto do número de folhas vivas por perfilho pelo filocrono; A Duração de expansão das folhas (DEF) - produto do número de folhas em expansão por perfilho pelo filocrono; a taxa de Elongação foliar (TAlF) - somatório de todo alongamento de lâmina foliar por perfilho dividido pelo número de dias do período de avaliação; taxa de senescência foliar (TSeF) decréscimo do comprimento da parte verde da lâmina foliar, obtida pela diferença entre a mensuração inicial e a final dividida pelo número de dias do período de avaliação.

Os dados meteorológicos referentes ao período experimental (Tabela 1) mostram que os valores médios observados de temperatura e precipitação ficaram próximos ao normal, caracterizando-se como um verão de clima ameno, em que as condições climáticas não foram limitantes para a produção.

Tabela 1 - Médias de temperatura máxima $\left(\mathrm{T}^{\circ} \mathrm{C}\right.$ Máx.), mínima $\left(\mathrm{T}^{\circ} \mathrm{C}\right.$ Mín.), média $\left(\mathrm{T}^{\circ} \mathrm{C}\right.$ Média), precipitação (mm) e insolação (horas) observadas (O) nos meses de Dezembro de 2012 a Abril de 2013, e média dos últimos 30 anos de observação (M)

\begin{tabular}{lllllllllll}
\hline \multirow{2}{*}{ Mês } & \multicolumn{2}{l}{$\mathbf{T}^{\circ} \mathbf{C}$ Max } & \multicolumn{2}{l}{$\mathbf{T}^{\circ} \mathbf{C}$ Mín } & \multicolumn{2}{l}{$\mathbf{T}^{\circ} \mathbf{C}$ Média } & \multicolumn{2}{l}{ Precip. -mm } & \multicolumn{2}{l}{ Insol. - hs } \\
\cline { 2 - 11 } & $\mathbf{O}$ & $\mathbf{M}$ & $\mathbf{O}$ & $\mathbf{M}$ & $\mathbf{O}$ & $\mathbf{M}$ & $\mathbf{O}$ & $\mathbf{M}$ & $\mathbf{O}$ & $\mathbf{M}$ \\
\hline Jan. & 30,2 & 31,0 & 18,1 & 19,8 & 24,2 & 25,4 & 145,3 & 155,9 & 286,1 & 248,7 \\
Fev. & 29,8 & 30,1 & 19,0 & 19,5 & 24,4 & 24,8 & 97,7 & 128,5 & 207,1 & 201,5 \\
Março & 26,6 & 29,0 & 16,4 & 18,3 & 21,5 & 23,6 & 188,6 & 124,4 & 181,0 & 212,1 \\
Abril & 26,3 & 25,7 & 14,4 & 15,0 & 20,4 & 20,3 & 147,4 & 152,3 & 209,6 & 178,7 \\
\hline
\end{tabular}

\section{Fonte: INMET}

O delineamento experimental utilizado foi o inteiramente casualizado, com medidas repetidas no tempo, com três tratamentos e duas repetições. Todas as variáveis foram testadas quanto à normalidade pelo teste Shapiro-Wilk. Os resultados das variáveis morfogênicas foram submetidos à análise de variância em nível de 5\% de significância, utilizando o PROC MIXED (modelos mistos). O critério de informação para a melhor estrutura de covariância foi o menor valor de AIC. As análises foram realizadas com auxílio do pacote estatístico SAS versão 9.1.3 (2009). 


\section{Resultados e discussão}

Houve diferença ( $\mathrm{P}<0,05$; Tabela 2) para as variáveis: número de folhas vivas (NFV, folhas/perfilho) e taxa de Elongação foliar (TAlF, $\mathrm{cm} /{ }^{\circ} \mathrm{GD}$ ) do sorgo forrageiro, que foram influenciadas pelos níveis de suplementação. Não houve interação $(\mathrm{P}>0,05)$ entre os níveis de suplementação e períodos de avaliação para essas variáveis. No presente estudo, o mais alto nível de suplementação correspondeu aos menores valores para as características apresentadas.

Tabela 2 - Médias e erro padrão para Número de folhas vivas (NFV, folhas/perfilho) e Taxa de Elongação foliar (TAlF, cm/ $/{ }^{\circ} \mathrm{GD}$ ) do sorgo forrageiro pastejado por novilhos recebendo diferentes níveis de suplementação

\begin{tabular}{|c|c|c|c|c|c|c|}
\hline \multirow{2}{*}{$\begin{array}{l}\text { CARACTERÍSTICA } \\
\text { MORFOGENICA }\end{array}$} & \multicolumn{3}{|c|}{ NÍVEIS DE SUPLEMENTAÇÃO } & \multirow[t]{2}{*}{$\mathbf{E P}^{\mathbf{l}}$} & \multirow[t]{2}{*}{$\mathbf{P}^{2}$} & \multirow[t]{2}{*}{$\begin{array}{c}\text { Trat. } x \\
\text { Per. }^{3}\end{array}$} \\
\hline & S 0,8 & S 1,0 & $\mathrm{~S} 1,2$ & & & \\
\hline NFV & $3,55^{\mathrm{a}}$ & $3,34^{\mathrm{a}}$ & $2,77^{b}$ & 0,18 & 0,047 & 0,631 \\
\hline TAlF & $0,08^{2}$ & $0,09^{\mathrm{a}}$ & $0,06^{\mathrm{b}}$ & 0,01 & 0,048 & 0,366 \\
\hline
\end{tabular}

Médias seguidas de letras distintas diferem entre si $(\mathrm{p}<0,05)$.

${ }^{1}$ Erro padrão da média ${ }^{2}$ Probabilidade ${ }^{3}$ Interação tratamento $\mathrm{x}$ período

$\mathrm{O}$ número de folhas vivas (NFV) foi maior para os tratamentos $\mathrm{S} 0.8$ e S 1.0 (3,55 e 3,34 folhas/ perfilho), enquanto o tratamento com maior nível de suplementação (S 1.2) apresentou menor NFV (2,77 folhas/perfilho). Isso pode ter ocorrido porque sob desfolhações frequentes em lotação contínua, há pouca competição por luz devido à remoção constante de área foliar pelos animais, de tal forma que as plantas desenvolvem uma resposta fotomorfogênica a um microclima com altas intensidades luminosas ${ }^{(12)}$. Esses resultados podem indicar ainda que houve maior uso da forragem pelos animais com o menor nível de suplementação alimentar. Portanto, a suplementação alimentar representa uma estratégia de manejo que influencia as características morfogênicas NFV e TAIF.

Segundo Hodgson ${ }^{(13)}$, Lemaire e Chapman ${ }^{(14)}$ e Nabinger ${ }^{(15)}$ o NFV é uma característica determinada basicamente pela genética da espécie, no entanto, pode sofrer variações em função do ambiente e manejo imposto à pastagem. Esses fatores irão determinar, através do mecanismo decorrente do tempo limitado de vida da folha, o momento em que para cada folha que senesce ocorra o surgimento de uma nova folha.

Essa característica também se referencia ao potencial de perfilhamento, no qual cada gema axilar associada a uma folha gerada tem potencial de gerar um novo perfilho, e dessa forma, alterar a estrutura da comunidade de plantas ${ }^{(16)}$. O elevado número de folhas vivas é uma característica estrutural desejável, pois indica acentuada capacidade da pastagem em armazenar forragem verde devido ao maior potencial para assimilação de carbono, captura de energia e capacidade de retenção de reservas, o que provavelmente resultará em rebrote mais vigoroso ${ }^{(17)}$. Resultados semelhantes foram encontrados por Silva et al. ${ }^{(8)}$ que avaliaram as características morfogênicas de diferentes híbridos de sorgo submetidos à adubação nitrogenada $(3,83 ; 3,20 ; 3,41$ e 3,62 folhas/perfilho).

A taxa de Elongação foliar (TAlF) foi inferior nas plantas em que o nível de suplementação dos animais foi maior, sendo $0,08 \mathrm{~cm} /{ }^{\circ} \mathrm{C}$ no tratamento $\mathrm{S} 0,8,0,09 \mathrm{~cm} /{ }^{\circ} \mathrm{C}$ no tratamento $\mathrm{S} 1,0$ e 0,06 $\mathrm{cm} /{ }^{\circ} \mathrm{C}$ no tratamento S1,2. Segundo Skinner e Nelson ${ }^{(18)}$, a zona de alongamento foliar é um local ativo e de grande deposição de nutrientes, principalmente de N, ou seja, o potencial fotossintético da 
planta é determinado no início do período de alongamento das folhas. No entanto, essas diferenças podem acarretar em práticas de manejo diferenciadas, em relação à produção de forragem de melhor qualidade, visto que a fração folha pode influenciar positivamente a eficiência de pastejo e o valor nutritivo da forragem produzida, além de fortes indicativos de que a TAlF é, dentre as variáveis morfogênicas, a que isoladamente mais se correlaciona com a massa seca da forragem ${ }^{(19)}$.

Gomide et al. ${ }^{(6)}$ avaliaram os atributos estruturais e produtivos do capim-Marandu sob três níveis de suplementação $(0,2,0,6$ e $1 \%$ do peso vivo $)$ e quatro ciclos de pastejo e verificaram que a suplementação não afetou os atributos morfogênicos do capim.

Para Taxa de aparecimento foliar (TApF), Taxa de senescência foliar (TSeF) e Filocrono (FILO) não houve diferença $(\mathrm{P}>0,05$; Tabela 3$)$ entre os tratamentos e não houve interação $(\mathrm{P}>0,05)$ entre os níveis de suplementação e os períodos de avaliação. Para as variáveis: Duração de Vida das folhas (DVF) e Duração de expansão das folhas $(\mathrm{DEF})$ houve efeito significativo $(\mathrm{P}<0,05)$ entre os períodos de avaliação.

Tabela 3 - Médias e erro padrão para Taxa de aparecimento foliar (TApF, cm/ $\left./{ }^{\circ} \mathrm{GD}\right)$, Taxa de senescência foliar (TSeF, cm/ $/{ }^{\circ} \mathrm{GD}$ ), Filocrono (FILO, ${ }^{\circ} \mathrm{GD}$ ), Duração de vida da folha (DVF, $\left.{ }^{\circ} \mathrm{GD}\right)$ e Duração de expansão da folha (DEF, $\left.{ }^{\circ} \mathrm{GD}\right)$ do sorgo forrageiro pastejado por novilhos recebendo diferentes niveis de suplementação

\begin{tabular}{|c|c|c|c|c|c|c|}
\hline \multirow{2}{*}{$\begin{array}{l}\text { CARACTERISTICA } \\
\text { MORFOGENICA }\end{array}$} & \multicolumn{3}{|c|}{ NÍVEIS DE SUPLEMENTAÇÃO } & \multirow[t]{2}{*}{$\mathbf{E P}^{\mathbf{l}}$} & \multirow[t]{2}{*}{$\mathrm{P}^{2}$} & \multirow[t]{2}{*}{$\begin{array}{c}\text { Trat. } x \\
\text { Per. }^{3} \\
\end{array}$} \\
\hline & S 0,8 & S 1,0 & $\mathrm{S} 1,2$ & & & \\
\hline TApF & 0,0041 & 0,0043 & 0,0039 & 0,0004 & 0,65 & 0,65 \\
\hline TSeF & 0,05 & 0,06 & 0,11 & 0,04 & 0,46 & 0,46 \\
\hline FILO & 283,96 & 265,21 & 278,62 & 16,88 & 0,58 & 0,58 \\
\hline DVF & 1081,1 & 986,25 & 788,79 & 116,99 & 0,17 & 0,17 \\
\hline \multirow[t]{3}{*}{ DEF } & 350,58 & 312,83 & 326,36 & 9,90 & 0,06 & 0,20 \\
\hline & \multicolumn{3}{|c|}{ PERÍODOS DE AVALIAÇÃO } & $\mathbf{E P}^{\mathbf{l}}$ & $\mathbf{P}^{2}$ & $\begin{array}{c}\text { Trat. } x \\
\text { Per. }^{3}\end{array}$ \\
\hline & P1 & P2 & P3 & & & \\
\hline DVF & $1211,82^{2}$ & $1010,79^{b}$ & $633,53^{\mathrm{c}}$ & 43,38 & $<.0001$ & 0,17 \\
\hline DEF & $406,21^{2}$ & $429,25^{\mathbf{a}}$ & $154,30^{b}$ & 32,50 & 0,0003 & 0,20 \\
\hline
\end{tabular}

Médias seguidas de letras distintas diferem entre si $(p<0,05)$.

${ }^{1}$ Erro padrão da média ${ }^{2}$ Probabilidade ${ }^{3}$ Interação tratamento $x$ período

A taxa de aparecimento foliar (TApF) é uma característica de extrema importância para a planta uma vez que a lâmina foliar é a responsável pela interceptação de luz, além de ser a variável central que determina a morfogênese em gramíneas. A semelhança entre os resultados observados nos tratamentos pode ser explicada pela dependência da variação da temperatura e, portanto, sofrer menos influência do manejo. A taxa de aparecimento foliar não é afetada por uma desfolhação que remova apenas algumas folhas por perfilho, mas é diminuída quando todas as folhas do perfilho são removidas ${ }^{(20)}$.

A Taxa de Senescência foliar (TSeF) responde diretamente a mudanças na massa de forragem, em função de sub ou superpastejo decorrentes da mudança nas taxas de lotação. A similaridade dessa variável nos tratamentos indica a adequação da taxa de lotação utilizada para manter as massas de forragem. A senescência foliar reduz a quantidade de forragem de qualidade, pois as porções verdes da planta são as mais nutritivas para a dieta animal ${ }^{(21)}$.

O filocrono indica o tempo, em acúmulo de graus-dia ou dias, necessário para o surgimento de uma nova folha no perfilho. $\mathrm{O}$ uso do conceito de graus-dia permite integrar ao calendário humano uma 
unidade de tempo às quais as plantas são sensíveis, independente das temperaturas a elas impostas a cada dia. Silva et al. ${ }^{(7)}$ observaram valores de filocrono de 10,53, 12,82 e 15,10 dias/folha, em híbridos de sorgo submetidos a diferentes doses de nitrogênio. Esses resultados, se calculados em graus-dia, são semelhantes aos observados no presente estudo. Essa característica é relativamente constante dentro de uma mesma espécie e assume uma importância considerável no manejo estratégico em pastejos rotativos. Um maior valor de filocrono indica menor velocidade de emissão de folhas, o que pode ser constatado neste estudo, ao observar os valores da TApF.

Para a duração de vida das folhas (DVF) verificada no sorgo forrageiro, os resultados obtidos foram numericamente maiores para os tratamentos com menores níveis de suplementação. Esses valores podem ser atribuídos ao valor do filocrono e ao NFV (Tabela 2) que foi alterado pelos níveis de suplementação. Essa justificativa baseia-se no fato de que a DVF foi calculada pela multiplicação dos dados de filocrono pelo número de folha viva por perfilho (NFV). Do ponto de vista de manejo, a maior DVF permite maximizar a eficiência de pastejo, em virtude da maior possibilidade de desfolhações em uma mesma folha durante seu período de $\operatorname{vida}^{(22)}$.

Segundo Santos et al. ${ }^{(23)}$ a duração de expansão foliar (DEF) é diretamente relacionada à TAlF, tempo que as folhas permanecem alongando. Os resultados obtidos no presente estudo para DEF podem ser atribuídos aos valores obtidos para a TAlF (Tabela 2), que foi alterada pelos níveis de suplementação, apresentando menores valores para maiores níveis de suplementação.

A diferença $(\mathrm{P}<0,05)$ entre os períodos de avaliação para DVF e DEF pode ser atribuída ao ciclo fenológico das plantas, que à medida que avança apresentam maior senescência, alongamento de colmos e menores investimentos em lâminas foliares. Segundo Quadros et al. ${ }^{(24)}$, ocorre uma alteração de prioridade na alocação das reservas, que deixam de ser destinadas às folhas, promovendo redução na elongação foliar, para serem gastas no alongamento dos entrenós do colmo.

Houve interação $(\mathrm{P}<0,05$; Tabela 4) entre os níveis de suplementação e períodos de avaliação para a altura de dossel (ALDOS). À medida que avançou o período de avaliação e aumentou o nível de suplementação, a altura do dossel foi diminuindo. Ressalta-se que a altura do dossel do pasto é um dos fatores que pode influenciar a taxa de aparecimento foliar devido ao aumento do comprimento da bainha das folhas sucessivas de gramíneas, havendo uma maior demora no surgimento das folhas acima do pseudocolmo ${ }^{(14)}$.

Tabela 4 - Altura de dossel (ALDOS, cm) e Altura de pseudocolmo (CPC, $\mathrm{cm})$ do sorgo forrageiro pastejado por novilhos recebendo diferentes niveis de suplementação

\begin{tabular}{|c|c|c|c|c|c|c|}
\hline \multirow{3}{*}{$\begin{array}{c}\text { Niveis de } \\
\text { suplementação }\end{array}$} & \multicolumn{3}{|c|}{ Altura de dossel (cm) } & \multirow{3}{*}{ Média } & \multirow{3}{*}{$\mathbf{E P}^{\mathbf{l}}$} & \multirow{3}{*}{ Trat. x Per. ${ }^{2}$} \\
\hline & \multicolumn{3}{|c|}{ Períodos de avaliação } & & & \\
\hline & 1 & 2 & 3 & & & \\
\hline $\mathrm{S} 0,8$ & $68,31^{\mathrm{ab}}$ & $54,49^{\mathrm{ab}}$ & $32,92 \mathrm{bc}$ & 51,91 & 8,79 & $<.0001$ \\
\hline $\mathrm{S} 1,0$ & $84,28^{2}$ & $60,49^{\mathrm{ab}}$ & $32,79^{\mathrm{c}}$ & 59,19 & & \\
\hline $\mathrm{S} 1,2$ & $86,73^{\mathrm{ab}}$ & $55,91^{\mathrm{bc}}$ & $28,20^{c}$ & 56,95 & & \\
\hline Média & $79,77^{\mathrm{A}}$ & $56,96^{\mathrm{B}}$ & $31,30^{\mathrm{C}}$ & & & \\
\hline \multicolumn{7}{|c|}{ Altura de pseudocolmo $(\mathrm{cm})$} \\
\hline S 0,8 & $21,33^{\mathrm{ab}}$ & $21,91^{2 b}$ & $12,93^{b c}$ & 18,72 & 2,54 & 0,044 \\
\hline $\mathrm{S} 1,0$ & $25,96^{\mathrm{a}}$ & $26,95^{\mathrm{a}}$ & $11,08^{c}$ & 21,33 & & \\
\hline $\mathrm{S} 1,2$ & $22,87^{\mathbf{a}}$ & $27,90^{\mathbf{2}}$ & $10,10^{\mathrm{c}}$ & 20,29 & & \\
\hline Média & $23,39^{A}$ & $25,59^{A}$ & $11,37^{\mathrm{B}}$ & & & \\
\hline
\end{tabular}

Letras minúsculas diferem entre linhas e colunas

Letras maiúsculas diferem entre linhas

${ }^{1}$ Erro-padrão da média ${ }^{2}$ Interação tratamento $\mathrm{x}$ periodo 
O efeito de interação $(\mathrm{P}<0,05)$ entre os níveis de suplementação e os períodos de avaliação também foi verificado para o comprimento de pseudocolmo (CPC) do sorgo forrageiro. O menor valor de CPC $(10,10 \mathrm{~cm})$ foi verificado no último período de avaliação no tratamento com maior nível de suplementação. Pode-se considerar ainda que o pastejo mais intenso no início do período de avaliação, tenha resultado na eliminação do meristema apical de muitos perfilhos, resultando em um comprimento reduzido de pseudocolmo, e dessa forma as folhas mais novas fizeram menor percurso para se expor ${ }^{(18)}$.

O CPC apresentou correlação negativa $\left(\mathrm{r}^{2}=0,52 ; \mathrm{P}<.0001\right)$ com o número de folhas vivas (NFV), à medida que aumenta o CPC diminui o NFV. E correlação positiva $\left(\mathrm{r}^{2}=0,52 ; \mathrm{P}<.0001\right)$ com altura de dossel (ALDOS). O CPC determina a distância que a folha percorre para emergir, vale ressaltar que seu alongamento, além de reduzir a relação folha/colmo, diminui a densidade de folhas verdes, contribuindo para o acúmulo de material senescente ${ }^{(25)}$, entretanto, pode apresentar efeito negativo sobre o aproveitamento e a qualidade da forragem produzida, agravando o pastejo seletivo dos $\operatorname{animais}^{(26)}$.

$\mathrm{O}$ comprimento final de lâminas foliares $(\mathrm{CFL})$ também foi influenciado $(\mathrm{P}<0,05$; Figura 1$)$ de forma interativa entre os níveis de suplementação e os períodos de avaliação (Figura 1). O CFL foi semelhante entre os níveis de suplementação no primeiro e segundo período de avaliação, no entanto no terceiro período os valores constatados foram menores, especialmente quando o nível de suplementação foi maior.

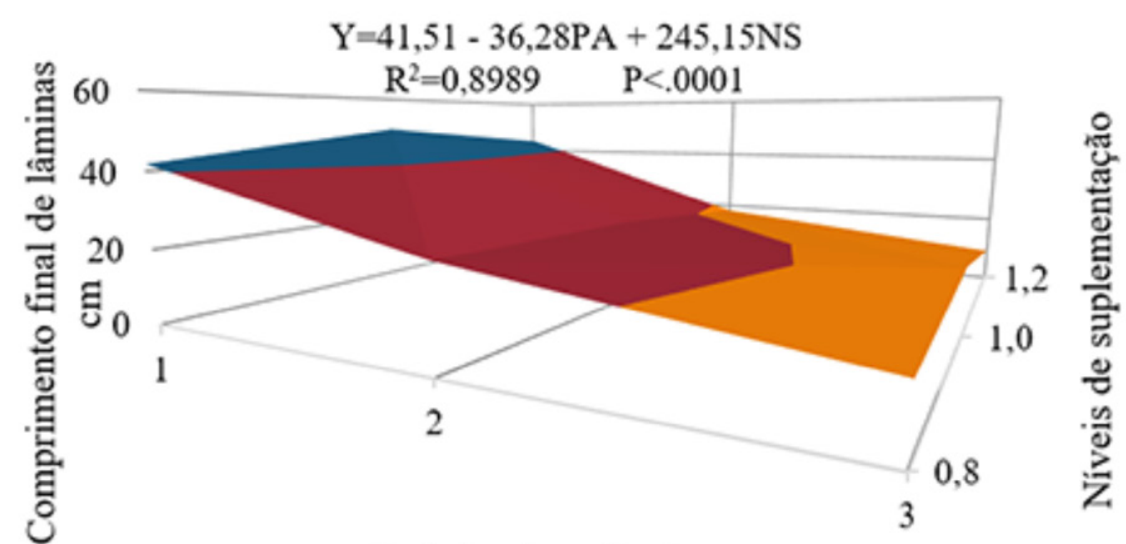

Periodos de avaliação

$=0-20=20-40 \quad=40-60$

Figura 1. Comprimento final de lâminas foliares de acordo com os níveis de suplementação (NS) e os períodos de avaliação (PA) do sorgo forrageiro.

O CFL apresentou correlação com a altura de dossel $\left(\mathrm{r}^{2}=0,87 ; \mathrm{P}<.0001\right)$. A redução na altura de dossel refletiu na redução do CFL. Com o rebaixamento do dossel, houve redução no pseudocolmo (Tabela 4) e o percurso das folhas mais novas para se expor foi menor. Assim, a distância percorrida pela folha, do ponto de conexão com o meristema até a extremidade do pseudocolmo, foi menor, resultando no seu menor comprimento ${ }^{(18)}$.

O comprimento de lâmina se deve também à altura de pseudocolmo, em função do aparecimento da 
folha corresponder à cessação da multiplicação celular, após a qual existe apenas a fase de expansão celular e, por isso, a altura do pseudocolmo determina o número de células e, consequentemente, o comprimento da lâmina, para determinadas condições de crescimento ${ }^{(27)}$.

O CFL apresentou correlação com o NFV $\left(\mathrm{r}^{2}=0,54 ; \mathrm{P}<.0001\right)$. À medida que diminuiu o CFL diminuiu o NFV, uma possível justificativa é em função da diferença entre as alturas de dossel, uma vez que, em alturas de dossel maiores a intensidade de consumo das folhas é menor, resultando em um maior número de folhas por perfilho. Assim, o CFL é uma característica plástica responsiva à intensidade de desfolhação, podendo ser uma estratégia morfológica de escape da planta ao pastejo ${ }^{(28)}$.

\section{Conclusão}

A suplementação alimentar de animais mantidos sob pastejo contínuo em pastagem de sorgo forrageiro afeta as características morfogênicas do pasto, quanto maior o nível de suplementação, menores os valores encontrados para o NFV e a TAlF. O período de avaliação influenciou na duração de vida das folhas e duração de expansão das folhas. A interação entre período de avaliação e níveis de suplementação influenciaram as características: altura de dossel, comprimento final da lâmina e o comprimento de pseudocolmo.

\section{Referências}

1. Soares AB, Carvalho, PCF, Nabinger C, Semmelmann C, Trindade JK, Guerra E, Freitas TS, Pinto CE, Fontoura Junior A. Produção animal e de forragem em pastagem nativa submetida a distintas ofertas de forragem. Ciência Rural. 2005; 35:1148-1153. http://www.scielo.br/pdf/cr/v35n5/a25v35n5.pdf.

2. Neumann M, Restle J, Souza ANM, Pellegrini LG, Zanette PM, Normberg JL, Sandini IE. Desempenho vegetativo e qualitativo do sorgo forrageiro (Sorghum bicolor X Sorghum sudanense) em manejo de cortes. Revista Brasileira de Milho e Sorgo. 2011; 9(3):298-313.

3. Pedreira MS, Reis RA, Berchielli TT, Moreira AL, Coan RM. Características Agronômicas e Composição Química de Oito Híbridos de Sorgo (Sorghum bicolor (L.) Moench). Revista Brasileira de Zootecnia. 2003; 32(5):1083-1092. http://www.scielo.br/pdf/rbz/v32n5/17890.pdf.

4. Costa NL, Moraes A, Gianluppi V, Bendahan AB, Magalhães JÁ. Acúmulo de forragem e características morfogênicas e estruturais de Trachypogon plumosus, durante o período seco, nos cerrados de Roraima. Bioscience Journal. 2012; 28:515 526. http://www.seer.ufu.br/index.php/biosciencejournal/article/viewFile/13314/9741

5. Roman J, Rocha MG, Genro TCM, Santos DT, Freitas FK, Montagner DB. Características produtivas e estruturais do milheto e sua relação com o ganho de peso de bezerras sob suplementação alimentar. Revista Brasileira de Zootecnia. 2008; 37:205 211.http://www.scielo.br/pdf/rbz/v37n2/05.pdf.

6. Gomide CAM, Reis RA, Simili FF, Moreira AL. Atributos estruturais e produtivos do capim-marandu em resposta à suplementação alimentar de bovinos e a ciclos de pastejo. Pesquisa Agropecuária Brasileira. 2009; 44 (5):526-533. http://www.scielo.br/pdf/pab/v44n5/v44n5a13.pdf

7. Silva WL, Basso FC, Ruggieri AC, Vieira BR, Alves PLCA, Rodrigues JAS. Características morfogênicas e estruturais de híbridos de sorgo submetidos a adubação nitrogenada. Revista Brasileira de Ciências Agrárias. 2012; 7(4): 691-696. http://www.agraria.pro.br/sistema/index. 
php?journal=agraria\&page $=$ article $\&$ op $=$ viewArticle $\&$ path $\% 5 \mathrm{~B} \% 5 \mathrm{D}=\mathrm{v} 7 \mathrm{i} 4 \mathrm{a} 1698$

8. EMPRESA BRASILEIRA DE PESQUISA AGROPECUÁRIA - EMBRAPA. Sistema brasileiro de classificação dos solos. Brasília: Embrapa-SPI; Rio de Janeiro: Embrapa-CNPS, 412p. 1999.

9. MORENO, J.A. Clima do Rio Grande do Sul. Porto Alegre: Secretaria da Agricultura, 1961. 41p.

10. Mott GO, Lucas HL. The desing. conduct. and interpretation of grazing trials on cultivated and improved pastures. In: INTERNATIONAL GRASSLAND CONGRESS. 1952;6:1380-1385 http://www.scielo.br/scielo. php?script $=$ sci nlinks\&ref $=000150 \& p i d=S 1516-3598201000030000200023 \& \operatorname{lng}=$ en

11. Carrère P, Louault F, Soussana JF. Tissue turnover within grass-clover mixed swards grazed by sheep. Methodology for calculating growth, senescence and intake fluxes. Journal of Applied Ecology. 1997; 34(2):333-348. https://www.jstor.org/stable/2404880?seq=1\#page_scan_tab_contents

12. Lemaire G. Ecophysiology of grasslands: Dynamics aspects of forage plant populations in grazed swards. INTERNATIONAL GRASSLAND CONGRESS. 2001; 19.29-37. http://www.internationalgrasslands.org/ files/igc/publications/2001/tema1-1.pdf.

13. Hodgson J. Grazing management: Science into practice. Longman Handbooks in Agriculture, New York: John Wiley \& Sons; 1990. 203p.

14. Lemaire, G.; Chapman, DF. Tissue flows in grazing plant communities. In: Hodgson J, Illius AW. (Eds.). The ecology and management of grazing systems. Wallingford: CAB International, 1996. p.3-36.

15. Nabinger C, Carvalho PCF. Ecofisiología de sistemas pastoriles: aplicaciones para su sustentabilidad. Agrociencia. 2009;13(3):18-27. http://www.fagro.edu.uy/agrociencia/index.php/directorio/article/view/232

16. Lemaire G, Agnusdei M. Leaf tissue turnover and efficiency of herbage utilization. In: Lemaire G, Hodgson J, Moraes A, Carvalho PCF, Nabinger C. (Eds). Grassland ecophysiology and grazing ecology. London: CAB International. 2000; p.265-288.

17. Martuscello JA, Fonseca DM, Nascimento Jr D, Santos PM, Cunha DNFV, Moreira LM. Características morfogênicas e estruturais de capim-massai submetido a adubação nitrogenada e desfolhação. Revista Brasileira de Zootecnia. 2006; 35(3):665-671. http://www.alice.cnptia.embrapa.br/bitstream/doc/47465/1/ PROCIPMS2006.00014.pdf.

18. Skinner RH, Nelson CJ. Elongation of the grass leaf and its relationship to the phyllochron. Crop Science. 1995; 35(1): 4-10. doi:10.2135/cropsci1995.0011183X003500010002x

19. Horst GL, Nelson CJ, Asay KH. Relationship of leaf elongation to forage yield of tall fescue genotypes. Crop Science.1978;18(5):715-719. doi:10.2135/cropsci1978.0011183X001800050005x

20. Davies A. Leaf tissue remaining after cutting and regrowth in perennial ryegrass. Journal of Agricultural Science. 1974; 82(1):165-172. https://doi.org/10.1017/S0021859600050334

21. Magalhães JA, Carneiro MSS, Andrade AC, Pereira ES, Andrade AP, Bakke AO, Rodrigues BHN, Mochel Filho WJE, Costa NL. Características morfogênicas e estruturais do capim-andropogon sob irrigação e adubação. Semina: Ciências Agrárias. 2013; 34 (5):2427-2436. http://www.uel.br/revistas/uel/index.php/ semagrarias/article/view/12002

22. Santos MER, Fonseca DM, Gomes VM, Gomide CAM, Nascimento Jr D, Queiroz DS. Capim-braquiária sob lotação contínua e com altura única ou variável durante as estações do ano: morfogênese e dinâmica de tecidos. Revista Brasileira de Zootecnia.2011;.40(11):2323-2331. http://www.scielo.br/scielo.php?pid=S1516$\underline{35982011001100007 \& \text { script }=\text { sci_abstract\&tlng }=\text { pt }}$ 
23. Santos AB, Quadros FLF, Confortin ACC, Seibert L, Ribeiro BSMR, Severo PO, Casanova PT, Machado GKG. Morfogênese de gramíneas nativas do Rio Grande do Sul (Brasil) submetidas a pastoreio rotativo durante primavera e verão. Ciência Rural. 2014; 44(1):97-103. http://www.scielo.br/scielo.php?script=sci arttext\&pid=S0103-84782014000100016

24. Quadros FLF, Bandinelli DG, Pigatto AGS, Rocha MG. Morfogênese de Lolium multiflorum Lam. E Paspalum urvillei Steud sob níveis de adubação de fósforo e potássio. Ciência Rural. 2005; 35(1):181-186. http://www.scielo.br/scielo.php?script=sci arttext\&pid=S0103-84782005000100029

25. Castagnara DD, Mesquita EE, Neres MA, Oliveira PSR, Deminicis BB, Bamberg R. Valor nutricional e características estruturais de gramíneas tropicais sob adubação nitrogenada. Archivos de Zootecnia. 2011; 60 (232):931-942. http://dx.doi.org/10.4321/S0004-05922011000400010

26. Cândido MJD, Gomide CAM, Alexandrino E, Gomide JA, Pereira WE. Morfofisiologia do dossel de Panicum maximum cv. Mombaça sob lotação intermitente com três períodos de descanso. Revista Brasileira de Zootecnia. 2005; 34(2):406-415. http://dx.doi.org/10.1590/S1516-35982005000200007

27. Duru M, Ducrocq H. Growth and senescence of the successive grass leaves on a tiller ontogenic development and effect of temperature. Annals of Botany. 2000; 85(5):635-643. https://doi.org/10.1006/anbo.2000.1116

28. Paula CCL, Euclides VPB, Lempp B, Barbosa RA, Montagner DB, Carloto MN.et. al. Acúmulo de forragem, características morfogênicas e estruturais do capim-marandu sob alturas de pastejo. Ciência Rural. 2012; 42(11) 2059-2065. http://www.scielo.br/scielo.php?pid=S0103-84782012001100024\&script=sci abstract\&tlng $=\mathrm{pt}$ 